\title{
Perbedaan pengaruh model pembelajaran kontekstual dan media audiovisual dengan motivasi belajar terhadap hasil belajar senam lantai
}

\author{
Regi Indah Lestari \\ Universitas Negeri Jakarta. Jl. Rawamangun Muka, RT.11/RW.14, Rawamangun, Pulo \\ Gadung, Kota Jakarta Timur, Daerah Khusus Ibukota Jakarta 13220 \\ Email: regiindah@yahoo.co.id
}

\begin{abstract}
Abstrak
Tujuan dari penelitian ini adalah untuk mengetahui perbedaan pengaruh model pembelajaran kontekstual dan media audiovisual dengan motivasi belajar siswa terhadap hasil belajar senam lantai. Penelitian ini dilakukan pada siswa kelas VIII SMP Negeri 2 Ciawi. Penelitian ini menggunakan treatment by level $2 \times 2$. Populasi dalam penelitian ini terdiri dari 164 dan menggunakan sampel 32 siswa. Teknik analisa data adalah analisis varians dua jalur (ANAVA) dan dilanjutkan dengan uji Turkey pada tingkat signifikan $\alpha=0,05$. Hasil penelitian ini menunjukkan bahwa (1) nilai hasil belajar guling lenting pada perlakukan model pembelajaran kontekstual (A1) lebih rendah dari nilai yang menggunakan media audiovisuall (A2) di SMP Negeri 2 Ciawi (2). Terdapat interaksi antara model pembelajaran kontekstual dan media audiovisuall (A) dengan motivasi belajar (B) terhadap hasil belajar guling lenting di SMP Negeri 2 Ciawi (3). Nilai hasil belajar pada perlakuan model pembelajaran kontekstual dengan motivasi tinggi (A1B1) lebih rendah dari nilai menggunakan media audiovisuall dengan motivasi tinggi (A2B1) di SMP Negeri 2 Ciawi. Nilai hasil belajar guling lenting pada perlakukan model pembelajaran kontekstual dengan motivasi rendah (A1B2) lebih rendah dari penggunaan media audiovisuall dengan motivasi rendah (A2B2) di SMP Negeri 2 Ciawi.

Kata kunci: model pembelajaran kontekstual, media audiovisuall, motivasi belajar, senam guling lenting

\section{The difference in the influence of contextual learning models and audiovisual media with learning motivation on learning outcomes in floor gymnastics}

\begin{abstract}
The purpose of this research is to know the effect of contextual learning model and audiovisual media with students' learning motivation on the learning result of gymnastics floor. This research was conducted on the students of class VIII SMP Negeri 2 Ciawi. This study used treatment by level $2 \times 2$. The population in this study consisted of 164 and used 32 samples of students. The data analysis technique is a two-lane variance analysis (ANAVA) and followed by Turkey test at a significant level $\alpha=0.05$. The results of this study indicate that (1) the value of learning achievement of bolster lenting on the treatment of contextual teaching and learning model (A1) is lower than value using audiovisuall media (A2) in SMP Negeri 2 Ciawi (2). There is an interaction between contextual learning model and audiovisual media (A) with learning motivation (B) to the learning result of lump in the SMP Negeri 2 Ciawi (3). The value of learning outcomes in the treatment of contextual learning models with high motivation (A1B1) is lower than the value of using audiovisuall media with high motivation (A2B1) in SMP Negeri 2 Ciawi. The value of learning achievement of bolster lenting on the treatment of contextual learning model with low motivation (A1B2) is lower than the use of audiovisuall media with low motivation (A2B2) in SMP Negeri 2 Ciawi.
\end{abstract}


Keywords: contextual teaching and learning model, audiovisuall media \& learning motivation on gymnastics neck spring.

\section{PENDAHULUAN}

Pendidikan atau pengajaran tidak hanya menekankan perubahan pada segi pengetahuan (kognitf) saja, melainkan juga pada segi sikap (afektif) dan keterampilan (psikomotor), serta segi-segi lain yang dapat menunjang dan mempertahankan kwalitasnya. Seperti telah dijelaskan dalam Undang-undang RI nomor: 20 tahun 2003 (2003:5) bahwa pendidikan nasional yang diselenggarakan oleh pemerintah berfungsi untuk mengembangkan berbagai kemampuan dan membentuk watak serta peradaban bangsa yang bermartabat dalam rangka mencerdaskan kehidupan bangsa, yang bertujuan mengembangkan potensi peserta didik agar menjadi manusia yang paripurna yaitu manusia yang bertakwa pada Tuhan Yang Maha Esa, berakhlak mulia, sehat, berilmu, cakap dan mandiri serta menjadi warga negara yang bertanggung jawab.

Pendidikan Jasmani Olahraga dan Kesehatan merupakan bagian dari sistem pendidikan nasional bertujuan untuk mengembangkan dan meningkatkan kualitas fisik dan kualitas psikis serta nilai-nilai kehidupan anak didik.

Tugas guru dalam pembelajaran adalah memberikan bantuan dan memfasilitasi terhadap siswa dalam memahami materi yang disajikan dengan harapan melalui bantuan guru siswa tidak lagi mengalami kesulitan dalam belajar.

Dalam pembelajaran Pendidikan Jasmani, domain psikomotor merupakan domain paling utama. Oleh karena itu pembelajaran yang menggunakan konsep kearah penguasaan gerak dan tehnik dasar, sangat perlu diperhatikan secara sunguh-sungguh agar terhindar dari apa yang dikatakan "handicaving habbit" (kebiasaan yang salah). Terlebih dalam materi senam lantai apabila gerakan salah akan menimbulkan terjadinya cidera.

Senam lantai guling lenting merupakan salah satu materi dalam pendidikan jasmani di SMP kelas VIII yang masih sangat jarang diajarkan guru kepada siswanya. Dalam pembelajaran senam guling lenting terlihat juga siswa belum terlihat aktif dan penuh rasa takut dalam melakukannya. Beberapa faktor yang melatar belakanginya baik dari pihak guru, siswa, waktu maupun sarana prasarana.

Adapun yang peneliti temui pada pengalaman mengajar antara lain:

1. Sarana Prasana yang kurang;

2. Guru merasa khawatir siswa mengalami cedera yang fatal;

3. Guru kurang menguasai dedaktik dan metodik materi senam;

4. Minat siswa yang kurang untuk mengikuti materi pembelajaran senam.

5. Adanya perasaan takut dan risi pada diri siswa untuk melakukan gerakan senam lantai.

Senam lantai termasuk ke dalam kelompok senam artistik di mana senam artistik ini menurut Agus Mahendra (2001:12) merupakan penggabungan antara aspek tumbling dan akrobatik untuk mendapatkan efek-efek artistik dan gerakan-gerakan yang dilakukan pada alat-alat tertentu. Efek artistiknya dihasilkan dari besaran (amplitudo) gerakan serta kesempurnaan gerak dalam menguasai tubuh ketika melakukan berbagai posisi.

Keberhasilan proses kegiatan belajar mengajar mata pelajaran pendidikan jasmani dapat diukur dari keberhasilan siswa yang mengikuti kegiatan tersebut. Keberhasilan tersebut tidak harus maksimal seperti gerak yang sempurna layaknya seorang atlet senam lantai. Namun dari pemahaman dan peningkatan dari kemampuan awal dan motivasi yang tinggi untuk mengikuti pembelajaran merupakan suatu keberhasilan dalam proses pembelajaran.

Model pembelajaran dan alat bantu pembelajaran diharapkan siswa dapat menerima dan menjadi daya tarik tersendiri terhadap materi pembelajaran keterampilan senam guling lenting sehingga siswa siap mengikuti dan termotivasi belajar dengan demikian tujuan pembelajaran akan mudah tercapai.

Dari hasil penelitian mengenai media pembelajaran audiovisual untuk pembelajaran senam lantai yang dilakukan oleh Luluk Indah dan Nanik Indahwati, 2015 hasilnya adalah media audiovisual dapat membedakan hasil belajar pada gerak senam lantai pada saat pre test dan post tes dan dapat meningkatkan hasil belajar senam lantai. 
Menurut hasil penelitian Sri Winarni, 2005 Pendekatan kontekstual diharapkan mampu menjadi pendekatan yang dapat mewujudkan tercapainya tujuan mata pelajaran Pendidikan Jasmani dalam Kurikulum 2004, hasil pembelajaran diharapkan lebih bermakna bagi siswa. Proses pembelajaran berlangsung alamiah dalam bentuk kegiatan siswa bekerja

dan mengalami, bukan transfer pengetahuan dari guru ke siswa. Strategi pembelajaran sangat menentukan hasil. Pengalaman gerak yang diperoleh siswa diharapkan bukan karena mencontoh atau meniru guru akan tetapi siswa menemukan pola geraknya sendiri dengan bantuan/fasilitas dari guru.

Berdasarkan masalah yang diuraikan diatas peneliti tertarik untuk melakukan penelitian dengan judul Perbedaan Pengaruh Model Pembelajaran Kontekstual dan Media Audiovisual dengan Motivasi Belajar Terhadap Hasil Belajar Senam Lantai Kelas VIII di SMP Negeri 2 Ciawi Kab Bogor.

\section{METODE}

Dalam penelitian eksperimen ini dilibatkan tiga variabel (1). variabel bebas adalah model pembelajaran kontekstual dan media audiovisual (2). Variable terikat adalah hasil belajar guling lenting dan (3). Variabel atribut adalah motivasi belajar. Motivasi belajar rendah dan motivasi belajar tinggi. Desain yang digunakan dalam penelitian ini adalah treatment by lavel $2 \times 2$.

Tabel 1. Disain Treatment By Level $2 \times 2$

\begin{tabular}{lll}
\hline & $\begin{array}{l}\text { Model Pembelajaran } \\
\text { Kontekstual (A1) }\end{array}$ & $\begin{array}{l}\text { Media Pembelajaran } \\
\text { Audiovisual (A2) }\end{array}$ \\
\hline Motivasi Tinggi (B1) & A1B1 & A2B1 \\
Motivasi Rendah (B2) & A1B2 & A2B2 \\
\hline
\end{tabular}

Keterangan :

A1B1 = Kelompok siswa yang memiliki motivasi belajar tinggi yang diajar dengan konsep Model pembelajaran kontekstual

A2B1 = Kelompok siswa yang memiliki motivasi belajar tinggi yang diajar dengan konsep media pembelajaran audiovisaul.

A1B2 = Kelompok siswa yang memiliki motivasi belajar rendah yang diajar dengan konsep model pembelajaran konstektual.

A2B2 = Kelompok siswa yang memiliki motivasi belajar rendah yang diajar dengan konsep media pembelajaran audiovisual.

\section{HASIL DAN PEMBAHASAN}

\section{Terdapat perbedaan pengaruh model pembelajaran kontekstual dengan media pembelajaran audiovisual terhadap hasil belajar guling lenting.}

Berdasarkan rangkuman hasil analisis perhitungan (ANAVA) pada taraf signifikan $\alpha=0,05$, didapat $q_{0}=5,69$ dan $q t=3,3142$ dengan demikian $q_{0}>$ qt sehingga Ho ditolak. Sehingga dapat disimpulkan bahwa secara keseluruhan terdapat perbedaan pengaruh yang signifikan antara model pembelajaran kontekstual dengan media audiovisual terhadap hasil belajar guling lenting. Dengan kata lain bahwa hasil guling lenting menggunakan media pembelajaran audiovisual $(X=72,21$ dan SD $=17,21)$ lebih baik daripada hasil belajar guling lenting menggunakan model pembelajaran kontekstual $(X=67,00$ dan $S D=16,79)$. Ini berarti hipotesis penelitian pertama yang menyatakan bahwa terdapat perbedaan pengaruh model pembelajaran kontekstual dan media audiovisual terhadap keterampilan guling lenting telah teruji.

\section{Interaksi antara model pembelajaran kontekstual dan media pembelajaran audiovisual terhadap hasil belajar guling lenting}

Pada interaksi perlakuan dengan motivasi, nilai sig sebesar 0,013 (lebih kecil dari 0,05), artinya ada interaksi antara model pembelajaran kontekstual dan media audiovisual yang berpengaruh sangat signifikan terhadap hasil belajar guling lenting. 


\section{Terdapat perbedaan antara model pembelajaran kontekstual dan media pembelajaran audiovisual terhadap hasil belajar guling lenting bagi siswa yang memiliki motivasi belajar tinggi.}

Perhitungan analisis varians tahap lanjut dengan uji Tukey untuk membandingkan kelompok motivasi belajar tinggi kedua strategi pembelajaran.

Tabel 2. rangkuman hasil perhitungan uji turkey

\begin{tabular}{cccc}
\hline $\begin{array}{c}\text { Kelompok yang } \\
\text { dibandingkan }\end{array}$ & $\begin{array}{c}\text { Harga Perbedaan } \\
\text { Rerata Absolut (qo) }\end{array}$ & $\begin{array}{c}\text { Harga Kritis } \\
\text { HSD (qt) }\end{array}$ & Keterangan \\
\hline A1B1 dan A2B1 & 4,56 & 3,0970 & Signifikan \\
\hline
\end{tabular}

Berdasarkan tabel rangkuman hasil perhitungan uji turkey menunjukkan bahwa harga Qhitung $(\mathrm{Q})=4,56$ lebih besar daripada Qtabel $=3,097$ atau Qhitung > Qtabel pada taraf signifikan a 0.05 , dengan demikian hipotesis nol $(\mathrm{Ho})$ ditolak dan hipotesis alternatif $(\mathrm{H} 1)$ diterima, artinya, bahwa hasil belajar guling lenting bagi kelompok motivasi belajar tinggi yang diajar dengan model pembalajaran kontekstual ( $X=75,56$ dan SD $=12,81$ ) lebih tinggi daripada yang diajar dengan media pembalajaran audiovisual ( $X=71,001$ dan SD $=17,85$ ). Hal ini berarti hipotesis penelitian ketiga yang menyatakan bahwa : terdapat perbedaan antara model pembelajaran kontekstual dan media pembelajaran audiovisual terhadap hasil belajar guling lenting bagi siswa yang memiliki motivasi belajar tinggi telah teruji.

\section{Terdapat perbedaan antara model pembelajaran kontekstual dan media pembelajaran audiovisual terhadap hasil belajar guling lenting bagi siswa yang memiliki motivasi belajar rendah}

Perhitungan analisis varians tahap lanjut dengan uji Tukey untuk membandingkan kelompok motivasi belajar rendah. Perhitungan mengenai perbedaan pengaruh hasil belajar guling lenting yang diajar dengan model pembelajaran kontekstual dan media pembelajaran audiovisual secara lengkap dapat dilihat pada rangkuman hasil perhitungan uji Tukey dapat dilihat pada tabel berikut:

Tabel 3. Rangkuman hasil perhitungan uji Tukey

\begin{tabular}{cccc}
\hline $\begin{array}{c}\text { Kelompok yang } \\
\text { dibandingkan }\end{array}$ & $\begin{array}{c}\text { Harga Perbedaan } \\
\text { Rerata Absolut (qo) }\end{array}$ & $\begin{array}{c}\text { Harga Kritis } \\
\text { HSD (qt) }\end{array}$ & Keterangan \\
\hline A1B2 dan A2B2 & 15,9 & 3,0970 & Signifikan \\
\hline
\end{tabular}

Nilai kelompok motivasi belajar rendah dengan model pembelajaran kontekstual dibanding kelompok motivasi belajar rendah dengan media pembelajaran audiovisual Qhitung $(\mathrm{Qh})=$ 15,9 lebih besar daripada Qtabel = 3,0970 atau Qhitung > Qtabel pada taraf signifikan $\alpha$ 0.05, dengan demikian hipotesis nol (Ho) ditolak dan hipotesis alternatif $(\mathrm{H} 1)$ diterima, artinya, bahwa hasil belajar guling lenting bagi kelompok motivasi belajar rendah yang diajar dengan model pembalajaran kontekstual ( $X=58,44$ dan $S D=16,20$ ) lebih rendah daripada yang diajar dengan media pembalajaran audiovisual ( $X=74,38$ dan SD $=16,96$ ). Hal ini berarti hipotesis penelitian ketiga yang menyatakan bahwa : terdapat perbedaan antara model pembelajaran kontekstual dan media pembelajaran audiovisual terhadap hasil belajar guling lenting bagi siswa yang memiliki motivasi belajar rendah telah teruji.

Dengan ditemukannya pengaruh interaksi ini, dapat diartikan bahwa kedua metode pembelajaran tersebut memberikan pengaruh yang berbeda terhadap hasil belajar guling lenting dalam pembelajaran pendidikan jasmani disekolah. Apabila dikaitkan dengan motivasi belajar pada kelompok siswa yang memiliki motivasi belajar tinggi ternyata model pembelajaran kontekstual baik jika dibandingkan dengan media pembelajaran audiovisual, sedangkan pada siswa yang memiliki motivasi belajar rendah media pembelajaran audiovisual lebih baik jika dibandingkan dengan model pembelajaran kontekstual. 
Dari temuan ini mengindikasikan bahwa motivasi belajar perlu dipertimbangkan dengan metode pembelajaran pada materi pembelajaran guling lenting. Perlu diketahui bahwa materi guling lenting perlu dilatih dengan strategi pembelajaran dengan cara yang bervariasi agar siswa tidak bosan dan hasil belajar yang diharapkan dapat tercapai, untuk mencapai hasil belajar guling lenting yang baik dibutuhkan banyak belajar dengan banyak berlatih bisa dengan bantuan media audiovisual agar anak selalu termotivasi dalam melakukan gerakan yang lebih baik, dengan demikian motivasi belajar tersebut merupakan suatu penunjang yang sangat dibutuhkan dalam meningkatkan hasil belajar guling lenting

\section{KESIMPULAN}

Berdasarkan hasil analisis data, hasil pengujian hipotesis dan hasil pembahasan penelitian yang telah diperoleh maka dapat dijelaskan beberapa kesimpulan, implikasi penelitian dan sasaran sebagai berikut :

1. Secara keseluruhan penerapan model pembelajaran CTL dan media pembelajaran audiovisual berpengaruh terhadap hasil tes awal dan tes akhir pada keterampilan guling lenting.

2. Terdapat interaksi antara strategi pembelajaran dan motivasi belajar terhadap keterampilan guling lenting.

3. Terdapat pengaruh yang signifikan dalam penerapan model pembelajaran kontekstual dan media pembelajaran audiovisual terhadap keterampilan guling lenting bagi siswa yang memiliki motivasi tinggi.

4. Terdapat pengaruh yang signifikan dalam penerapan model pembelajaran kontekstual dan media pembelajaran audiovisual terhadap keterampilan guling lenting bagi siswa yang memiliki motivasi rendah.

\section{DAFTAR PUSTAKA}

Agus Mahendra. Pembelajaran Senam, Pendekatan Pola Gerak Dominan untuk Siswa SLTP. Jakarta: Depdiknas, 2001

Cheryl A. Coker., Motor Learning and Control for Practitioners. USA: Library of Congres Cataloging in Publication Data, 2004.

Cholik Mutohir: Penjelasan KTSP: Jakarta. 2006.

Departemen Pendidikan dan Kebudayaan, Petunjuk Teknis Pendidikan Jasmani , Jakarta: Depdikbud, 1995.

Depdiknas, Kamus Umum Bahasa Indonesia, Jakarta : Balai Pustaka, 2003.

Depdiknas. Materi Penataran Nasional Guru Penjas SMP Tk. Dasar Jakarta. 2004.

Frank M. Ferducci, Measurement Concepta in Physical Education, St. Louis Missouri: Mosby Company, 1980

Gallahue, David L., Understanding Motor Development Infants, Children, Adolescents, Adults, New York: McGraw Hill. 1998.

Hamzah B Uno. Teori Motivasi dan Pengukurannya. Jakarta. Bumi Aksara. 2007.

Harsono. Coaching dan Aspek-Aspek Psikologis Dalam Coaching. Jakarta P2PLPTK, 1988

Hartono. Motivasi Berprestasi Suatu Tinjauan dan Lintas Budaya Makalah. Surabaya. Magister Psikologi UNTAG, 1998.

Johnson Elaine B. Contextual Teaching and Learning, California: MMU. 2002.

Modul PLPG Pendidikan Jasmani dan Kesehatan. Universitas Pakuan, 2011.

Moerad Baso. Teknologi Pembelajaran dan Media Interaktif. Surabaya. Universitas PGRI Adibuana, 2006.

M. Nazir, Metode Penelitian. Bogor. Ghalia Indonesia, 2009.

Richard Arends, Learning to Teach: Belajar untuk Mengajar. Yogyakarta: Pustaka Pelajar. 2008. 
Robert N. Singer., Motor Learning and Human Performance, New York: MacMilan Publishing Co.,In, 1980.

Rusli Lutan., Belajar Keterampilan Motorik: Pengantar Teori dan Metode, Jakarta: Departemen Pendidikan dan Kebudayaan, Dirjend. Pendidikan Tinggi, 1988.

Richard A. Schmidt, "Motor Learning \& Performance". Los Angeles: Human Kinetics Books, 1991.

Syaiful Sagala. Konsep dan Makna Pembelajaran, Bandung: Alfabeta cet. IV, 2006.

Sadiman dkk. Media Pendidikan. Jakarta. Grafindo, 2004.

Sudjana. Strategi Pembelajaran. Bandung: Falah Production, 2005.

Sudjana, Metoda Statistika edisi ke- 5. Bandung. Tarsito, 1999.

Sugiyanto dan Sudjarwo, "Materi Pokok: Perkembangan dan Belajar Gerak, Buku Ir' Jakarta: UT, Depdikbud, 1991.

Suharsimi Arikunto . Prosedur Penelitian Suatu Pendekatan Praktek. Jakarta:Rineka Cipta, 1996.

Undang-Undang Republik Indonesia No. 20 Th. 2003. Jakarta, 2003.

Wingkel. WS. Psikologi Pembelajaran. Jakarta. Gramedia, 1987.

Wina Sanjaya, Strategi Pembelajaran Berorientasi Standar Proses Pendidikan. Jakarta: Prenada Media Group, 2008.

Winarno. Metodologi Pengajaran Nasional, Bandung Cemara, 1996.

Wikipedia http//www.wikipedia, 2011.

Luluk Indah dan Nanik Indahwati, Penerapan Media Audiovisual dalam gerak senam lantai terhadap hasil belajar siswa. http://ejournal.unesa.ac.id/index.php/jurnal-pendidikanjasmani/issue/archive. 2015

Sri Winarni, Pendekatan Kontekstual dalam Pendidikan Jasmani. https:/journal.uny.ac.id/index.php/jpji/article/view/4314. 2005 